\title{
Which components or attributes of biodiversity influence which dimensions of poverty?
}

\author{
Dilys Roe ${ }^{1 *}$, Max Fancourt ${ }^{2}$, Chris Sandbrook², Mxolisi Sibanda ${ }^{1}$ Alessandra Giuliani ${ }^{1}$ and Andrew Gordon-Maclean ${ }^{1}$
}

\begin{abstract}
Background: There is an explicit assumption in international policy statements that biodiversity can help in efforts to tackle global poverty. This systematic map was stimulated by an interest in better understanding the evidence behind this assumption by disaggregating the terms and asking - as our review question - which components or attributes of biodiversity influence which dimensions of poverty?

Methods: We employed a search strategy that covered peer-reviewed and grey literature. Relevant studies included in the map were those that described an interaction by poor people with biodiversity in non-OECD countries and documented some kind of contribution (positive or negative) to different aspects of their well-being.

Results: A total of 387 studies were included in the final systematic map. Of these 248 met our additional criteria that studies should include a measure of the contribution to poverty alleviation. The studies were widely distributed geographically. Ecological distribution was less well spread, however, with the largest number of studies focussed on forests. We found studies addressing 12 different dimensions of poverty/well-being - although the most commonly studied was income. Similarly we found studies addressing all levels of biodiversity from genes to ecosystems. The largest number of studies was focussed on groups of resources - particularly non-timber forest products. In most cases, abundance was the attribute that made biodiversity important for poverty alleviation/well-being, while diversity was the least frequently noted attribute.
\end{abstract}

Conclusions: The map highlights a number of apparent gaps in the evidence base. Very few studies documented any causal link between use of biodiversity and an impact on poverty. In the majority of the studies biodiversity was framed in terms of its value as a resource - in the form of specific goods that can be used to generate tangible benefits such as cash, food fuel. Very few studies explored the underpinning role of biodiversity in ecosystem service delivery for poverty alleviation, and fewer investigated the benefits of diversity as a form of insurance or adaptive capacity. This is where we suggest research should be prioritised.

Keywords: Biodiversity, Nature conservation, Wildlife conservation, Poverty, Livelihoods

\section{Background}

Biodiversity conservation and poverty alleviation are both important societal goals attracting increasing international attention. At first glance they may appear to be separate policy realms with little connection. The Convention on Biological Diversity (CBD), agreed in 1992, was drafted in response to escalating biodiversity loss and provides an international policy framework for biodiversity conservation activities worldwide. Similarly, the OECD International Development Targets of 1996 - reiterated as the

\footnotetext{
* Correspondence: dilys.roe@iied.org

${ }^{1}$ International Institute for Environment and Development (IIED), 80-86 Grays Inn Road, London WC1X 8NH, UK

Full list of author information is available at the end of the article
}

Millennium Development Goals (MDGs) in 2000 - focus international development efforts on global poverty alleviation.

However, there is an explicit assumption that conserving biodiversity (or reducing the rate of biodiversity loss) can help in efforts to tackle global poverty and enhance human well-being. Evidence of this assumption lies in the target that parties to the CBD agreed in 2002: "to achieve by 2010 a significant reduction of the current rate of biodiversity loss at the global, regional and national level as a contribution to poverty alleviation [emphasis added] and to the benefit of all life on earth" [1]. The development community also bought into this assumption: when the 
Millennium Development Goals (MDGs) were formulated in 2000, for example, Goal 7 included a target to "reverse the loss of environmental resources", one indicator of which was the area of land under protection for biodiversity. Subsequently, the CBD "2010 Target" was included as a new target within MDG7 following the 2006 UN General Assembly, with additional biodiversity indicators [2].

The reduction in the rate of biodiversity loss anticipated in the 2010 target was not achieved [3,4]. This continued loss of biodiversity is lamented not just for its own sake but for its potential implications for continued human well-being and poverty reduction. The 2010 progress report on the MDGs, for example, noted "The irreparable loss of biodiversity will also hamper efforts to meet other MDGs, especially those related to poverty, hunger and health, by increasing the vulnerability of the poor and reducing their options for development" [5]. A high level meeting at the September 2010 UN General Assembly further stressed the linkage, claiming: "preserving biodiversity is inseparable from the fight against poverty" [6]. The CBD's new Strategic Plan (2011-2020), agreed at the $10^{\text {th }}$ Conference of Parties in Nagoya, Japan in October 2010 continues to emphasise the link between achieving conservation goals and reducing poverty: its mission being to "take effective and urgent action to halt the loss of biodiversity in order to ensure that by 2020 ecosystems are resilient and continue to provide essential services, thereby securing the planet's variety of life, and contributing to human well-being, and poverty eradication." [7].

At some levels the relationship between biodiversity and poverty is absolute - biodiversity underpins the delivery of essential ecological services on which the whole of humanity is dependent. But there is certainly no linear relationship. For example, the Millennium Ecosystem Assessment (MA) suggested that while many millions of people have benefited from the transformation of ecosystems and exploitation of natural resources, the benefits have not been evenly or equitably distributed, with the poor being the biggest losers [8]. Other commentators have noted the dynamic and context-specific nature of the biodiversity conservation-poverty alleviation relationship [9] and have suggested that factors such as individual access to, and control over, resources; policies on poverty and biodiversity protection; population growth and density are critical in determining whether or not the existence, or use, of biodiversity leads to poverty reduction [10].

Biodiversity is defined by the $\mathrm{CBD}$ as "the variability among living organisms from all sources including, inter alia, terrestrial, marine and other aquatic ecosystems and the ecological complexes of which they are part; this includes diversity within species, between species and of ecosystems". This focus on variability is often missing, however, when assertions such as those above are made. The term biodiversity is often used to refer to the amount (in terms of abundance or biomass) of species or resources, or the extent of habitat rather than diversity per se $[11,12]$. Poverty is another term with many different definitions. The simplest usually relate to some level of material wealth - for example the Millennium Development Goal to "eradicate extreme poverty" refers to the billion-plus people whose income is less that US $\$ 1$ a day. However, poor people often do not define themselves in cash income terms - indeed the concept of cash is completely meaningless for some indigenous communities who live outside of the cash economy. It has therefore become increasingly recognised that poverty is multi-dimensional. The World Bank, for example, describes poverty as 'to be hungry, to lack shelter and clothing, to be sick and not cared for, to be illiterate and not schooled' [13] while Sen discusses poverty in terms of 'capabilities' to fulfil a productive life including good health, access to education and political freedom [14]. This conceptualisation of poverty is similar to that of human well-being, and indeed, poverty can be thought of as the opposite - or absence - of well-being [8].

Our research is stimulated by an interest in better understanding the evidence behind the broad claims made by the United Nations and others about the role of biodiversity in contributing to poverty alleviation. Disaggregating the terms and exploring which particular components/attributes of biodiversity are important to poor people and in what ways will help achieve this understanding.

\section{Objective of the review}

Systematic mapping is intended to provide an overview of evidence on broad topics - to describe the nature, volume and characteristics of research in a chosen field $[15,16]$. Systematic maps can be used as a tool for identifying where studies would lend themselves to robust synthesis - e.g. through a systematic review; and to identify knowledge gaps to inform new research initiatives. In this case, the overall objective of our systematic map was to describe the current state of the evidence base on biodiversity - poverty links. In particular we set out to explore the degree to which it disaggregates "biodiversity" and "poverty", its representativeness, the types of linkages that have been found, and the methods that have been used to analyse them. Figure 1 provides a conceptual framework diagram for the review.

\section{Defining the primary question components}

We had originally framed our primary research question as follows: Which components or attributes of biodiversity affect (positively or negatively) which dimensions of poverty? Following comments from a reviewer of a draft 


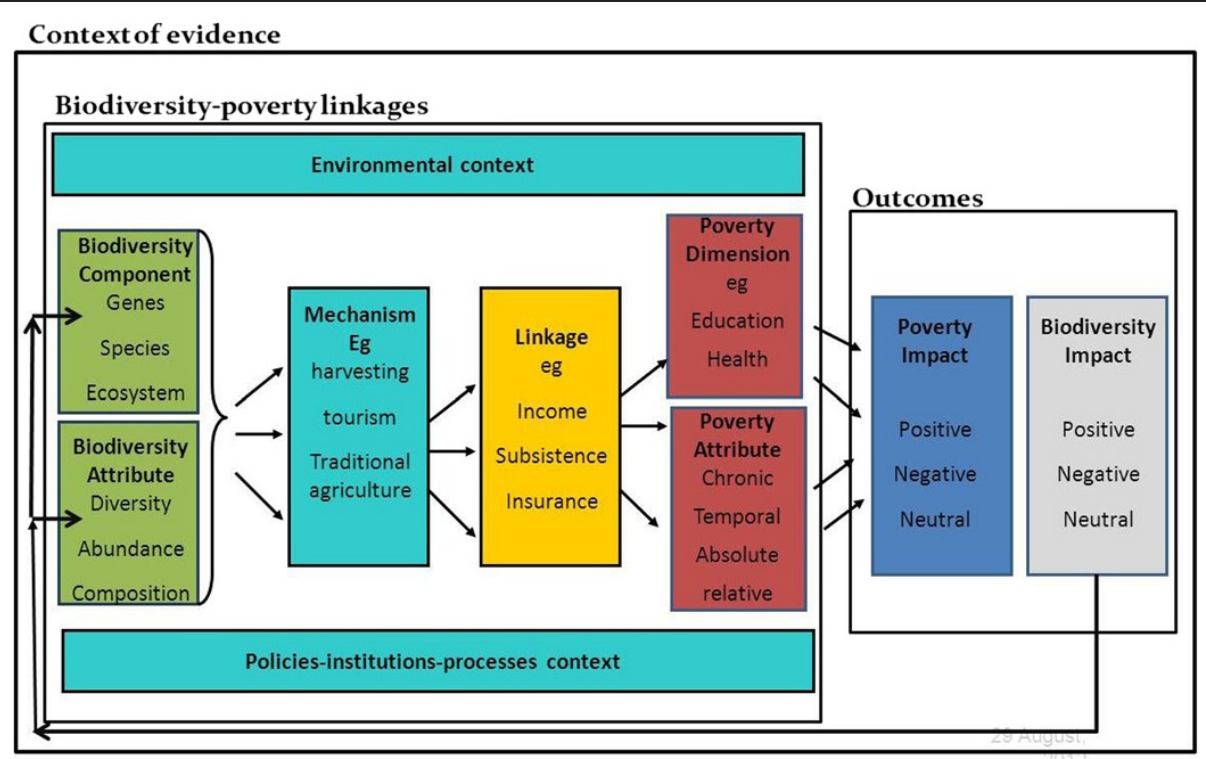

Figure 1 Conceptual framework for reviewing biodiversity-poverty linkages.

of this paper, and acknowledgment that we were not seeking solely to examine studies that had measured a quantifiable effect or impact of biodiversity on poverty we reframed the question to better reflect the broader nature of our enquiry, specifically: Which components or attributes of biodiversity influence (positively or negatively) which dimensions of poverty? Table 1 summarises the different components of our primary research question.

Our interpretation of the term "biodiversity" in this context merits some discussion. As we note in the Background section above, the CBD definition of biodiversity encompasses "living organisms from all sources". For the purposes of the map, however, we were predominantly interested in natural habitats and wild species - what Balmford et al. describe as "wild nature" [17] - rather than all living organisms. The line between what is wild and what is not is, however, very fuzzy. For example, we did not include mainstream agricultural crops in our interpretation of biodiversity but we did include indigenous varieties of crops and crop wild relatives, or locally domesticated wild species. Similarly, we did not include modern livestock as a component of biodiversity but we did include traditional breeds or landraces.

We also did not want to conduct a study on the health impacts of living pathogens so our interpretation of biodiversity also omitted micro-organisms, parasites and disease vectors such as mosquitoes. We recognise, however, that the impact of such living organisms on poverty is probably far more significant than that of any other component of biodiversity.

Finally, much has been written about the varied and complex inter-linkages between biodiversity and ecosystem services. In this review we have not covered the broad ecosystem service literature but only where a study has specifically linked the provision of a specific ecosystem service with particular components of biodiversity. Mace et al. [18] identify three different roles for biodiversity in ecosystem services: as a regulator of ecosystem processes; as a final ecosystem service; and as a good. Our review has encompassed studies on biodiversity in each of these roles but within that has predominantly adopted what Mace et al. would refer to as a "conservation perspective" where the focus is on "a subset of biodiversity that includes charismatic species and those on threatened species lists" [p21]. Specifically, we have focussed on a subset of biodiversity that is predominantly wild (or at least not domesticated to an industrial scale) and of a predominantly larger than micro-organism scale (but not ignoring wild genetic resources).

Table 1 Elements of the systematic map question

\begin{tabular}{llll}
\hline Subject & Intervention & Comparators & Outcomes \\
\hline Human individuals, households & Direct or indirect use or conservation & No use or conservation & Positive or negative effects on the \\
or communities, or nation states & of, or interaction with, one or more & of, or interaction & multi-dimensional poverty status of people \\
in developing countries & component of biodiversity & with, biodiversity & interacting with biodiversity in developing \\
& & countries & \\
\hline
\end{tabular}




\section{Methods}

\section{Searches}

\section{Search terms and languages}

We conducted all searches in English due to the linguistic competencies of the review team and also as one mechanism for restricting the scale of the review. Because we were interested in disaggregating broad claims about biodiversity and poverty we developed an extensive set of search terms that described different components of biodiversity and different dimensions of poverty. Our research protocol [19] describes in detail the precise steps we followed to develop and test the search terms, including consultation at an expert workshop in August 2012. Additional file 1 summarises the evolution of the final search string.

\section{Searches}

Our key sources of data were two online databases of peer-reviewed publications - SciVerse's Scopus [20], and ISI's Web of Science [21] both of which cover natural and social sciences. The search string described in Additional file 1 was used firstly in Scopus to search titles, abstracts and keywords and then in Web of Science to search the field code "Topic" which includes title, abstract and keywords. The search string was slightly modified when applied to Web of Science because of the different way it structures subject areas, and hence the subjects to which the search can be limited or that can be excluded. The results from the Scopus search were combined with the Web of Science results and screened for duplicates using bibliographic software Endnote and Zotero.

To cross-check the publications database searches, Google Scholar was searched just using the terms: "biodiversity" OR "wildlife" AND "poverty" OR "livelihoods" OR "poor". The first 50 'hits' were compared with the Web of Science and Scopus search returns to test their comprehensiveness. References returned by the Google Scholar search, but not found in the Web of Science and Scopus searches, were added to the reference list.

Finally, a sample of the grey literature to include was identified through a number of steps. First, a call was issued via the mailing list of the Poverty and Conservation Learning Group (PCLG) [22]; second, a selection was made of a manageable but representative (in terms of conservation or development focus) number of international organisations that are members of the PCLG and their websites searched for relevant documents (Table 2); and thirdly the PCLG bibliographic database was searched using the search terms- "poverty" OR "livelihoods" AND "biodiversity", OR "wildlife" OR "nature" OR "species".

\section{Estimating the comprehensiveness of the search}

Our use of disaggregated poverty and biodiversity terms in the search string was intended to ensure a comprehensive
Table 2 List of websites searched for grey literature

\begin{tabular}{|c|c|}
\hline Organisation & Website \\
\hline A Rocha International & www.arocha.org \\
\hline BirdLife International & www.birdlife.org \\
\hline CARE International & www.care-international.org/ \\
\hline Caribbean Natural Resources Institute & www.canari.org \\
\hline $\begin{array}{l}\text { Catholic Agency for Overseas } \\
\text { Development (CAFOD }\end{array}$ & www.cafod.org/uk \\
\hline $\begin{array}{l}\text { Centre for International } \\
\text { Forestry Research (CIFOR) }\end{array}$ & www.cifor.org \\
\hline Convention on Biological Diversity & www.cbdint \\
\hline $\begin{array}{l}\text { Department for International } \\
\text { Development (DFID), UK }\end{array}$ & $\begin{array}{l}\text { www.gov.uk/government/ } \\
\text { organisations/department-for- } \\
\text { international-development }\end{array}$ \\
\hline Food and Agriculture Organisation (FAO) & www.fao.org \\
\hline $\begin{array}{l}\text { International Institute for Environment } \\
\text { and Development (IIED) }\end{array}$ & www.iied.org \\
\hline $\begin{array}{l}\text { International Union for Conservation } \\
\text { of Nature (IUCN) }\end{array}$ & www.iucn.org \\
\hline $\begin{array}{l}\text { United Nations Environment } \\
\text { Programme }\end{array}$ & www.unep.org \\
\hline $\begin{array}{l}\text { United Nations Environment } \\
\text { Programme - World Conservation } \\
\text { Monitoring Centre }\end{array}$ & www.unep-wcmc.org \\
\hline $\begin{array}{l}\text { United Nations Development } \\
\text { Programme }\end{array}$ & www.undp.org \\
\hline $\begin{array}{l}\text { United States Agency for International } \\
\text { Development (USAID) }\end{array}$ & www.usaid.gov \\
\hline Wildlife Conservation Society (WCS) & www.wcs.org \\
\hline World Bank & www.worldbank.org \\
\hline $\begin{array}{l}\text { Worldwide Fund for Nature International } \\
\text { (WWF) }\end{array}$ & http://wwf.panda.org/ \\
\hline
\end{tabular}

search, including articles from non-traditional sources. Overall the search yielded 10,623 peer-reviewed and grey literature documents that we then screened for relevant titles (see below). However, despite the iterative development of the search terms and our broad search, the coding of papers that occurred during the data-extraction process (also described below) revealed some gaps in the search results that must be a consequence of the search terms and strings used (for example there were very few studies documenting the livelihoods impacts of the live animal trade). A further constraint was that we ran out of time to ask our expert group to review the final list of publications which would have helped in identifying key gaps. Finally, an obvious limitation is that we only included material written in English potentially excluding a wealth of studies from non-anglophone countries and organisations.

\section{Study inclusion criteria}

The inclusion/exclusion process took place through a number of stages, following our protocol [19]. Firstly, for the peer-reviewed literature, all article titles were reviewed 
and articles excluded if their titles did not meet the following criteria:

- Relevant population (s): the title makes mention of biodiversity (as interpreted above) in some form (broad terms, specific components).

- Relevant outcomes: the title makes mention of some aspect of poverty (or related terms such as livelihoods or wellbeing).

Secondly, all the abstracts of the articles passing the first stage of title review were read and any which did not meet the following criteria excluded:

- Relevant intervention (s): the study makes mention of an association between biodiversity use or nonuse and one or more dimensions of poverty or wellbeing.

In addition, the following exclusion criteria were applied at abstract level:

- Irrelevant countries: studies that were focussed only on OECD countries were excluded.

- Irrelevant interventions: studies that assessed the contribution of poverty to biodiversity loss/ environmental degradation.

- Irrelevant study design: theoretical studies such as models and scenarios.

At this stage we also excluded any articles that had passed the abstract screening but for which we were unable to obtain downloadable copies of the full text within the time and resources available.

The title review and abstract review stages were undertaken by two researchers and a kappa test was performed at each stage in order to check for consistency in the interpretation of the inclusion/exclusion criteria. The kappa test result was 0.804 at the title review stage (strength of agreement between the two researchers considered to be "very good") and 0.732 at the abstract review stage (strength of agreement considered to be "good"). For the grey literature the same two researchers - with proven consistency of judgement - reviewed all the titles. However it was often difficult to judge from the title whether the content of an article was relevant and so consequently many more articles were retained where there was uncertainty. The majority of grey literature articles did not have abstracts and so the abstract screening stage was omitted for these articles.

The final set of articles was exported from a Zotero library to a Microsoft Excel workbook. The workbook was structured so that each article could be analysed against a series of questions - as articulated in our data extraction strategy - and coding applied. Additional file 2 provides details of the list of questions and the coding strategy.

The final stage of inclusion/exclusion took place during data extraction. If, during the full text review and accompanying data extraction process, it became clear that studies did not meet the inclusion criteria above, then they were excluded and the reason for exclusion noted. Additionally, our data extraction framework was structured to explore in more detail any studies that actually included some measure of the contribution of biodiversity use/nonuse to one or more dimensions of poverty or wellbeing.

Once all the studies had been read and data extracted by an expanded team of five researchers, the final dataset was checked for anomalies, re-coded where necessary and analysed using descriptive statistical methods. The Excel workbook showing the final set of coded studies is included as Additional file 3.

\section{Study quality assessment}

As specified in our protocol [19] we did not seek to prejudge the 'quality' of different types of evidence in our mapping process, recognising that the type of evidence required depends on the specific question being asked and on the motivation and discipline of the questioner [23]. However, by describing the methods used by each study that we map we hope that we leave future researchers, practitioners and policy analysts better able to identify what evidence is and is not relevant for the specific questions they wish to answer.

\section{Results}

\section{Review statistics}

\section{Number and types of studies}

The search of publication databases was conducted on 23 October 2012 while the search of websites and other sources for grey literature was conducted between $1^{\text {st }}$ November 2012 and $31^{\text {st }}$ March 2013. A total of 387 studies were judged to have met the inclusion criteria based on title, abstract, and full text review and were included in the final systematic map. Of these 248 met our additional criteria that studies should include some kind of measure of the contribution to one or more dimensions of poverty/wellbeing. Figure 2 summarises the numbers of articles that were included at each stage of the process. A bibliography of the final set of articles included in the map is provided in Additional file 4 while the list of articles rejected at full text review is included as Additional file 5.

The majority of articles were journal papers $(n=294$, $76 \%$ of the full set and $n=180,73 \%$ of the subset with a poverty measure) followed by peer-reviewed grey literature $(n=47,12 \%$ of full set and $n=42,17 \%$ of subset) and non-peer reviewed published grey literature $(n=30$, $8 \%$ of full set and $n=16,2 \%$ of subset). We reviewed very 


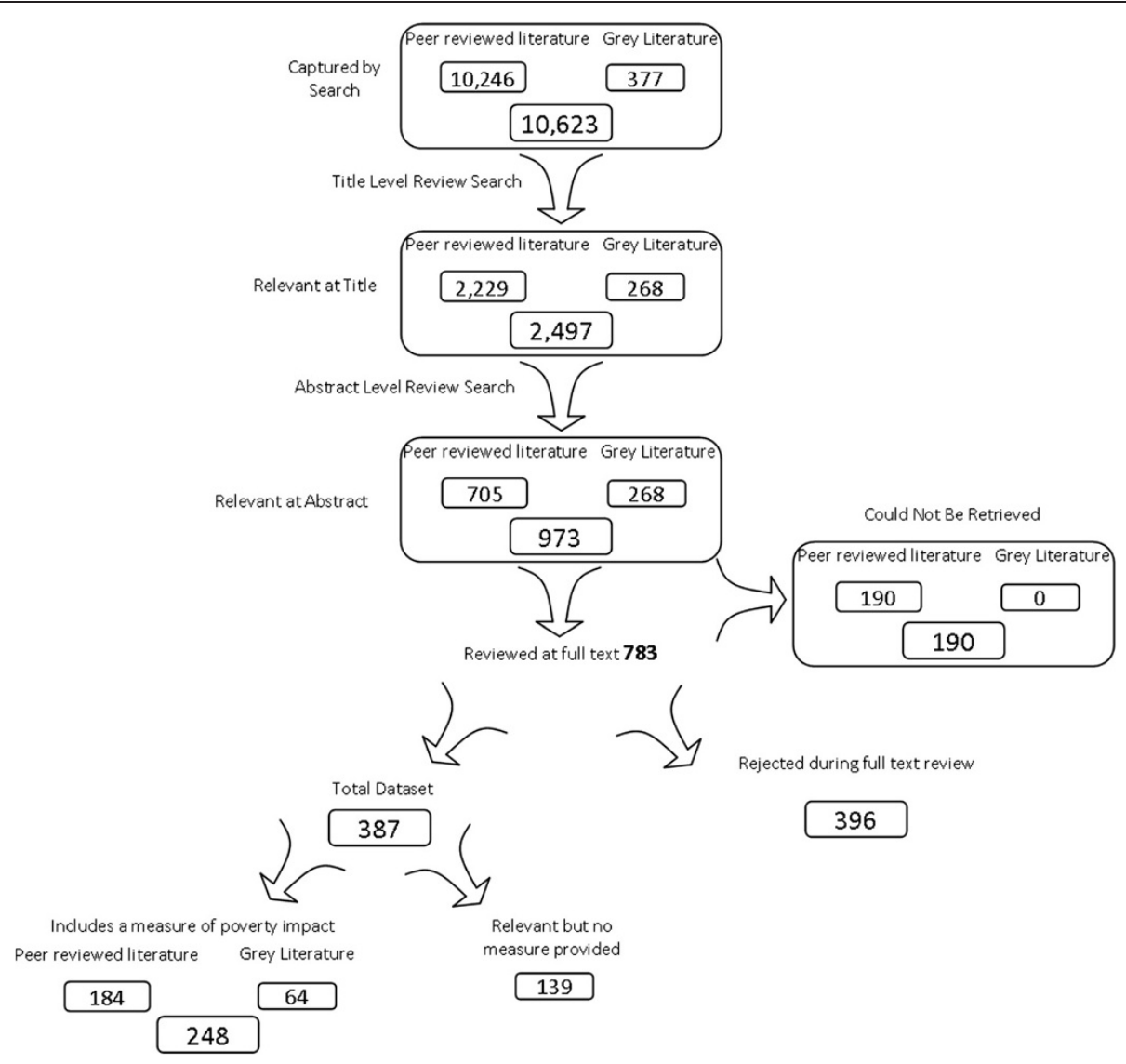

Figure 2 The number of articles retrieved in the initial search, and the numbers passing each subsequent stage of screening.

few books or conference proceedings. Some articles included multiple case studies and where these were substantive $(n=12)$ they were included as separate entries in the database. We set no date restrictions on our search and the earliest article retrieved was dated 1985. Figure 3 describes the number of articles published per year.

\section{Representativeness of studies Geographical coverage}

The studies were widely distributed, covering 27 countries from Africa, 16 from Asia, 13 from Latin America and 3 from Oceania (with some studies covering more than one country). The most commonly studied region

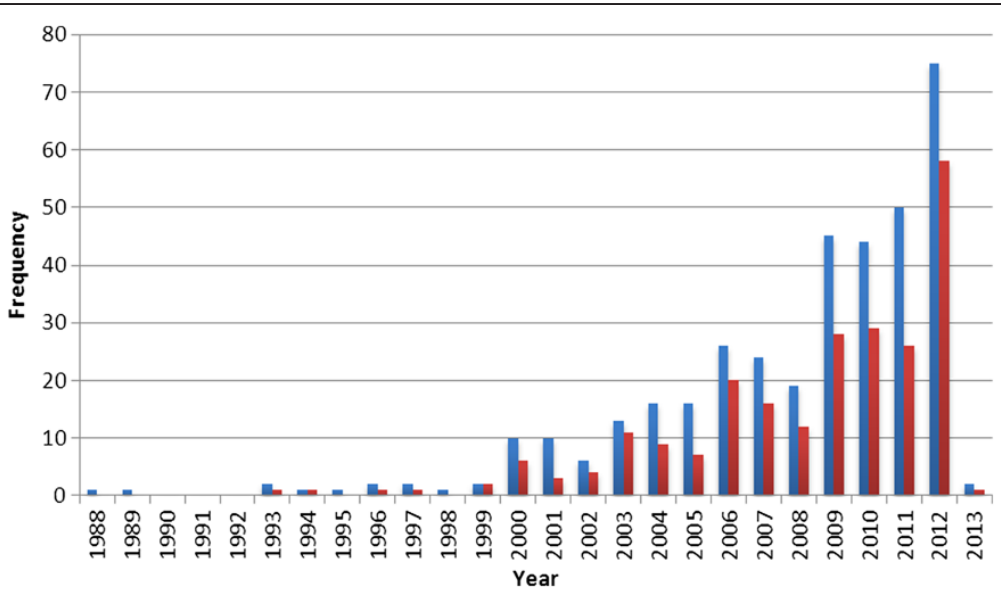

Figure 3 Trends in number of published studies per year (blue columns represent total dataset meeting primary inclusion criteria $(n=387)$; red columns represent subset with a measure of contribution of biodiversity to poverty $(n=248)$. 
was Africa ( $\mathrm{n}=169,43 \%)$ within which the most commonly studied country was South Africa $(n=31,18 \%)$. The next most studied region was Asia ( $n=142,36 \%)$ within which the most studied country was India $(n=45$, $32 \%)$. There was a smaller proportion of studies in Latin America - potentially reflecting our language bias $(n=54$, $14 \%)$ and Oceania $(n=3,>1 \%)$. A further 24 studies $(6 \%)$ were global in coverage. Figure 4 shows the regional distribution of studies.

\section{Ecological coverage}

Our assessment of the ecological distribution of studies employed a version of the IUCN habitats classification scheme [23] simplified by Birdlife [24]. By far the most studied habitat was forests $(n=202,52 \%$ of the full set of papers, $\mathrm{n}=125,52 \%$ of the subset with a poverty measure). The second most studied ( $n=88,23 \%$ of the full set; $n=49,17 \%$ of the subset) was terrestrial artificial habitats (this category includes, for example, agricultural land, pasture land, gardens). Wetlands $(n=40)$, marine $(n=31)$, coastlines $(n=29)$, savannah $(n=29)$ and grasslands $(n=24)$ were all relatively similarly studied, while the least studied habitats were artificial aquatic landscapes, mountains, deserts and introduced/exotic habitats. Figure 5 summarises the results.

\section{Description of studies}

The results presented below seek to describe the evidence base relevant to our conceptual framework in Figure 1. Moving from right to left across the framework, we describe the components and attributes of biodiversity that have been studied; the dimensions of poverty that the studies have highlighted these components of biodiversity contributing to; the mechanisms by which the link between biodiversity and poverty is made; and the outcomes - in terms of sustainability of biodiversity use and nature and scale of contribution to poverty alleviation or wellbeing. The presentation of results distinguishes between the full set of articles and the subset that includes some kind of quantification of the influence of biodiversity on poverty or wellbeing.

\section{Components and attributes of biodiversity studied}

The studies addressed different components of biodiversity - from genetic resources to ecosystems (Figure 6). We added the category "guilds" to capture studies on, for example, the role of pollinators. We made a distinction between studies that focussed on individual species and those that focussed on groups of species (for example African plains game, or "the big five"). We also distinguished studies that were focussed on particular types of resources - rather than specific species - for example non-timber forest products (NTFPs). This resources category was the most commonly studied component of biodiversity ( $n=146,38 \%$ of all papers) within which the most commonly studied type of resource was NTFPs ( $\mathrm{n}=134,92 \%)$. The least commonly studied were guilds $(n=3,<1 \%)$ and genetic resources $(n=19,5 \%)$. The remaining studies were relatively evenly distributed between ecosystems $(n=91,23 \%)$, species $(n=90,23 \%)$ and groups of species $(n=62,16 \%)$.

In most cases, the abundance or extent of biodiversity was the attribute that made it important for poverty alleviation ( $\mathrm{n}=268,70 \%$ of all papers) while diversity was the least frequently noted attribute $(n=83,21 \%)$.

\section{Dimensions and aspects of poverty studied}

The Ecosystem Services for Poverty Alleviation (ESPA) programme has produced a conceptual framework for understanding poverty [25]. This identifies - from a

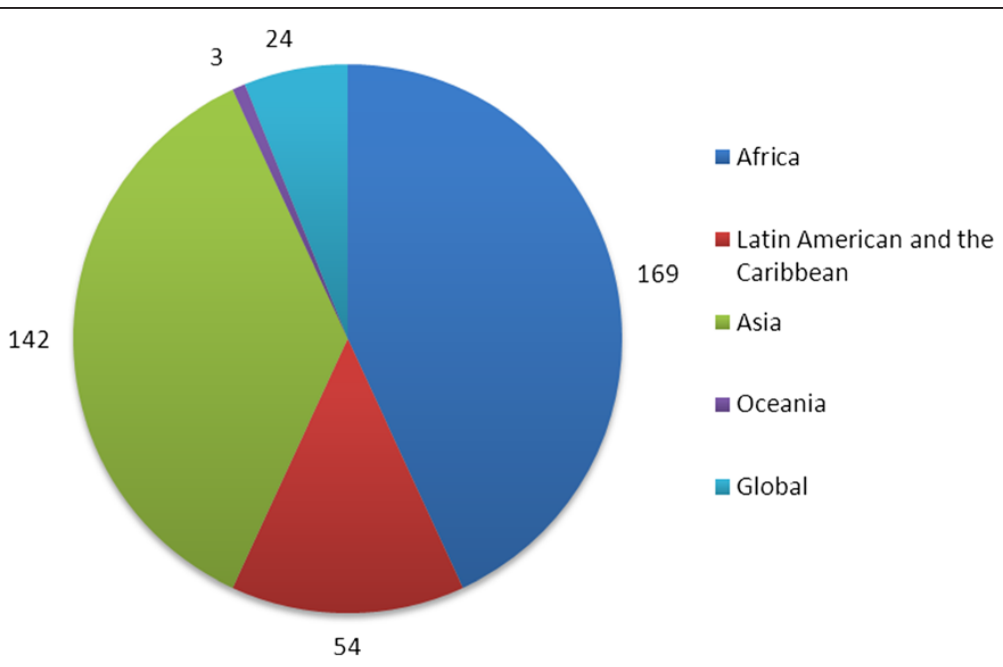

Figure 4 Geographical distribution of studies (NB some studies covered more than one location hence total number exceed $n=387$ studies). 


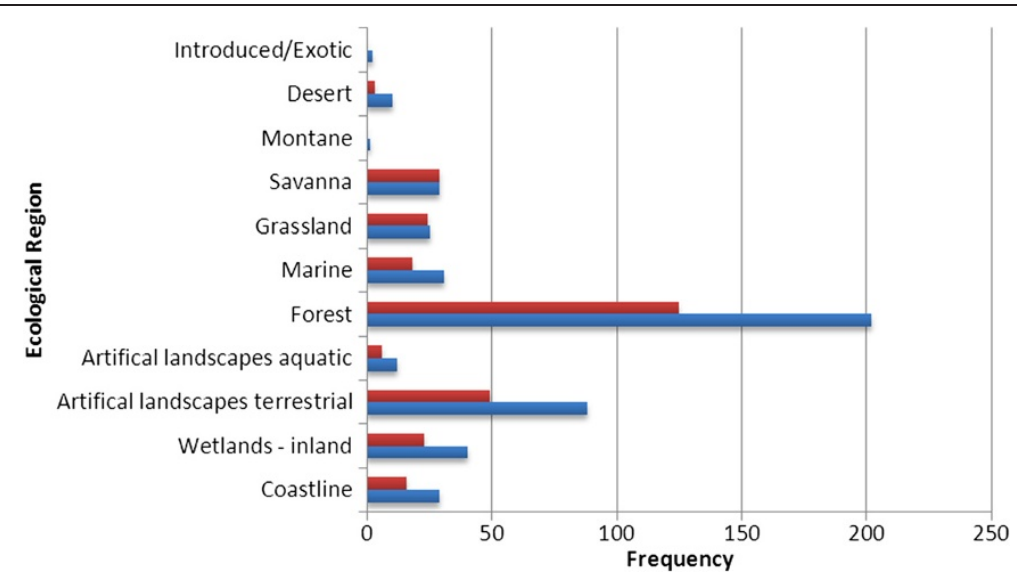

Figure 5 Distribution of studies in different ecological habitats (blue columns represent total dataset meeting primary inclusion criteria $(n=387)$; red columns represent subset with a measure of contribution of biodiversity to poverty $(n=248)$.

review of the literature - 19 commonly used dimensions of poverty. Our analysis only identified studies that addressed 11 of these, plus an additional dimension - energy security. Although most studies examined more than one dimension of poverty, the most commonly studied was income $(\mathrm{n}=270,70 \%$ of all papers, and $\mathrm{n}=$ $205,83 \%$ of papers with a poverty measure). Other commonly studied dimensions were food security $(n=124$, $32 \%$ of all papers) and asset accumulation ( $n=91,23 \%$ of all papers). The least commonly studied were energy, shelter and safe water. Figure 7 describes the frequency of study of each dimension.

The ESPA poverty framework highlights the dynamic nature of poverty and recommends that attention should be paid to both short term (temporal) poverty as well as long term, chronic poverty. It is also important to distinguish between absolute poverty - as measured against a defined poverty line - and relative poverty. Just over half
( $\mathrm{n}=196,51 \%)$ of the papers we reviewed specified the aspect of poverty being studied. Of these $61 \%(n=120)$ were concerned with relative poverty and $39 \%(n=76)$ were concerned with absolute poverty. Fewer studies $(\mathrm{n}=94,24 \%)$ considered poverty dynamics - that is, whether it is lasting or transitory - of which the majority $(\mathrm{n}=73,78 \%)$ focussed on chronic (persistent) poverty and only a small minority $(\mathrm{n}=21,22 \%)$ focussed on temporal (transient) poverty.

\section{Components of biodiversity associated with different dimensions of poverty}

We further analysed the dataset to explore which components of biodiversity were most commonly linked with which dimensions of poverty. We have already highlighted above that income was the most frequently cited dimension of poverty that biodiversity contributes to. Table 3 describes how the types of study with which

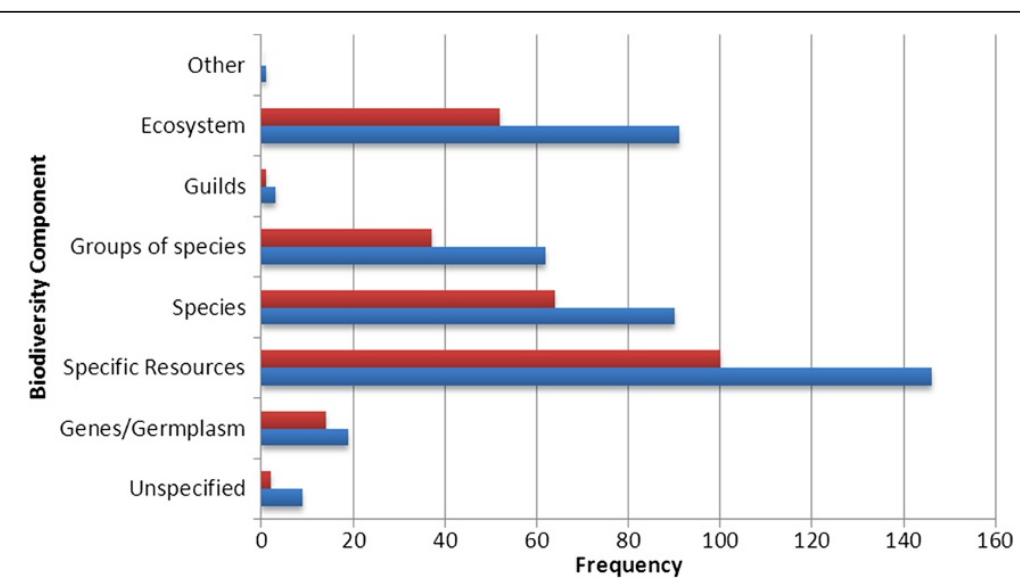

Figure 6 Frequency with which different components of biodiversity have been studied (blue columns represent total dataset meeting primary inclusion criteria; red columns represent subset with a measure of contribution of biodiversity to poverty). 


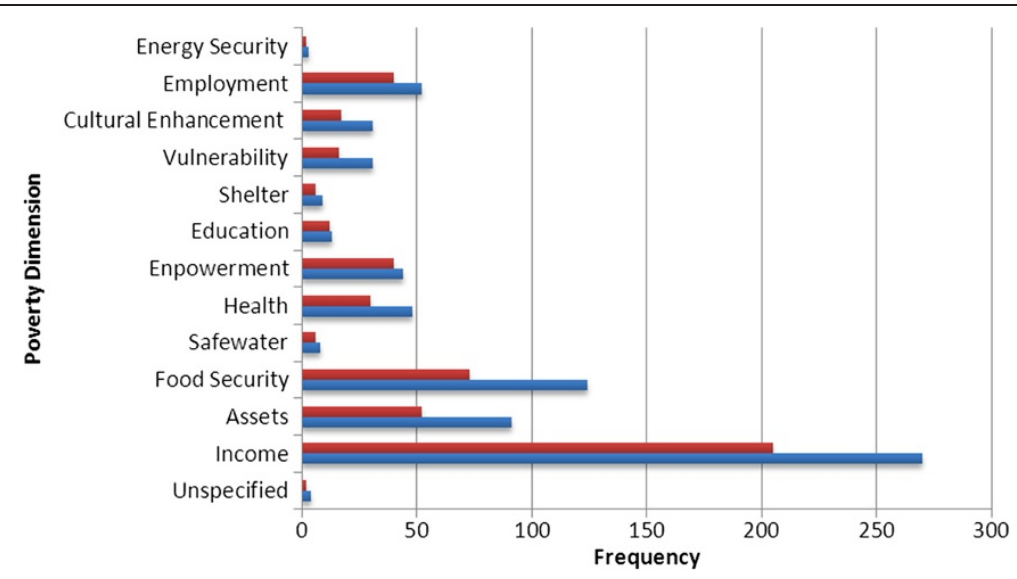

Figure 7 Dimensions of poverty studied (blue columns represent total dataset meeting primary inclusion criteria; red columns represent subset with a measure of contribution of biodiversity to poverty).

income is most commonly associated are those concerned with specific types of resources, individual species and groups of species, and ecosystems. Similarly we have already highlighted that specific resource types were the most commonly studied component of biodiversity. Further analysis shows that the most commonly cited dimensions of poverty that resources contribute to were income, assets and food security.

\section{Type of mechanisms linking bidiversity and poverty}

In our analytical framework we identified a number of "mechanisms" by which the link between biodiversity and poverty or wellbeing is achieved. We categorised these as direct use, indirect use, non-use, and "biodiversity disservices". For the purposes of this study we used "use" and "non-use" terminology in a slightly different way to that commonly used in the concept of total economic value (TEV) [26]. Our use of the term "direct use" is consistent with TEV and refers to the consumptive use of certain species or resources such as NTFPs for subsistence or tradable purposes. Indirect use refers to the benefits derived from biodiversity being left in situ rather than being removed or consumed and includes, for example use of biodiversity for tourism or for soil nutrient cycling. Non-use refers to the co-benefits that can arise from biodiversity management efforts. These first three categories all refer to the benefits that people get from biodiversity but we recognise that biodiversity can also impose costs. Our final category - "biodiversity disservices" therefore refers to the negative impacts that components of biodiversity can have on people. As noted in our introduction, we deliberately did not set out to retrieve studies on the health impacts of parasites and diseases - if we had we would expect this category to have a much higher frequency of papers.
The majority of studies falling into this category thus largely referred to cases of human-wildlife conflict.

We found that the most common mechanism for linking biodiversity and poverty was through direct use of different components of biodiversity (mentioned in $\mathrm{n}=$ $338,87 \%$ of all papers) (Figure 8). We further investigated the mechanism by which biodiversity and poverty are linked by identifying the precise mechanism, or form of use, described in the studies. Figure 9 illustrates the wide variety of mechanisms employed, with the most commonly identified being NTFP harvesting (noted in $203,52 \%$ of studies). We also found that for each of the different mechanisms studied, biodiversity contributed to multiple dimensions of poverty. This was particularly pronounced in studies of fishing, NTFPs, tourism and wild plant cultivation where almost all dimensions of poverty were considered in one or more study. Additional file 6 illustrates the numbers of studies that associate different mechanisms for using biodiversity with different dimensions of poverty.

Having identified the type of mechanisms by which biodiversity was linked to poverty we also looked at how the mechanism worked. We differentiated between use of biodiversity for subsistence purposes only or to generate a tradeable surplus or income. We also differentiated between immediate use and longer term contributions to livelihoods - for example through maintaining productive land and ecosystems. Finally we noted any studies that described the use of biodiversity as providing an emergency lifeline or safety net and those where it had a negative effect and actually undermined livelihood security. We found that the most commonly identified processes by which biodiversity affects poverty are through generating income $(n=316,82 \%$ of all papers $)$ and supporting subsistence needs ( $\mathrm{n}=271,70 \%$ of all papers). Less commonly identified processes were contributing to 


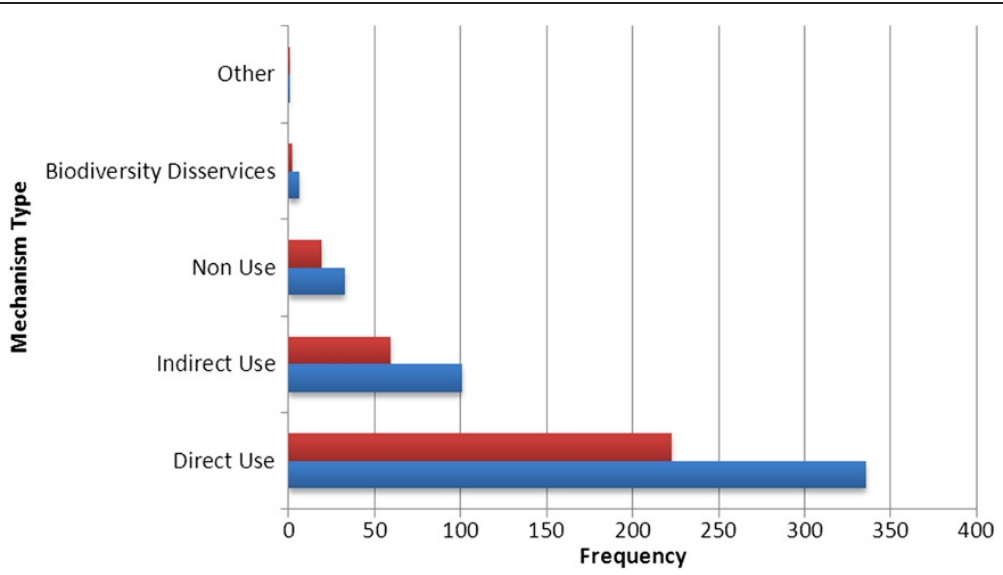

Figure 8 Mechanisms for linking biodiversity and poverty (blue columns represent total dataset meeting primary inclusion criteria; red columns represent subset with a measure of contribution of biodiversity to poverty).

longer term livelihood support ( $\mathrm{n}=78,20 \%$ of all papers) and acting as a safety net ( $\mathrm{n}=35,9 \%$ of all papers).

\section{Outcomes for poverty - nature and scale}

The overwhelming majority of papers $(\mathrm{n}=326,84 \%)$ described a positive contribution of biodiversity to poor peoples' wellbeing. However, only two-thirds of those reporting the positive contribution $(n=223,66 \%)$ actually included any measure of that contribution. Measures related to almost all the dimensions of poverty were used although the most common type of measure was income-related (used in $n=223$ of the 248 (90\%) papers that used a measure). The specific measures used varied quite considerably and included: absolute amount of income generated per capita or household from use of biodiversity; household or per capita income generated from biodiversity as a proportion of total household or per capita income; and, income equivalent of biodiversity-related household consumption). Non-income measures included increases in food availability and intake; numbers of jobs created; improvements in health; improvements in asset productivity.

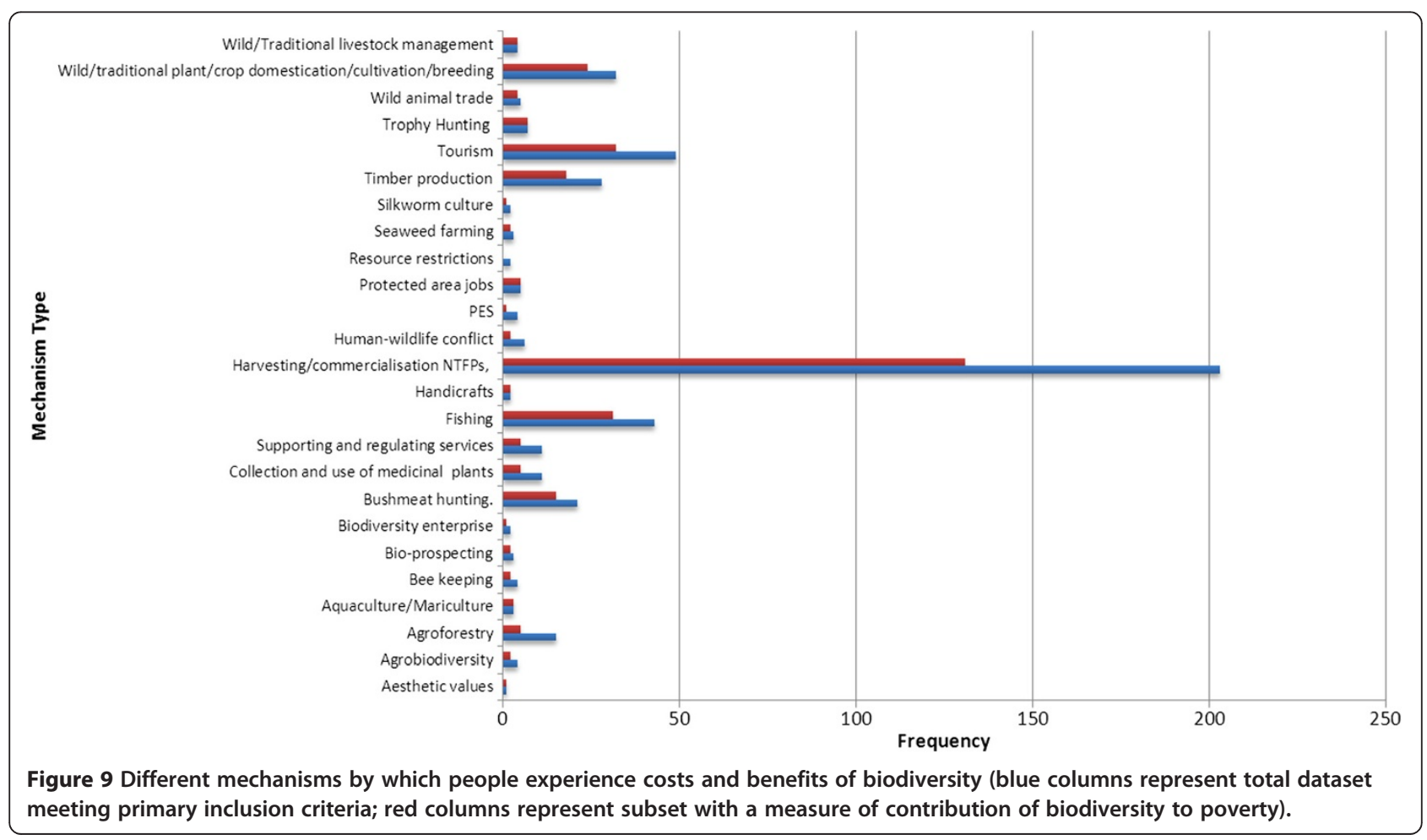


Table 3 Numbers of studies that associate different components of biodiversity with different dimensions of poverty

\begin{tabular}{|c|c|c|c|c|c|c|c|c|}
\hline & Unspecified & Genes/germplasm & Specific resources & Species & Groups of species & Guilds species & Ecosystems & Other \\
\hline Unspecified & 0 & 0 & 0 & 1 & 0 & 0 & 1 & 0 \\
\hline Income & 2 & 12 & 83 & 55 & 31 & 0 & 42 & 0 \\
\hline Assets & 0 & 1 & 21 & 12 & 7 & 1 & 18 & 0 \\
\hline Food security & 2 & 0 & 33 & 21 & 12 & 0 & 10 & 0 \\
\hline Safewater & 0 & 0 & 2 & 2 & 1 & 0 & 4 & 0 \\
\hline Health & 1 & 1 & 14 & 10 & 1 & 0 & 8 & 0 \\
\hline Enpowerment & 0 & 2 & 10 & 11 & 7 & 0 & 17 & 0 \\
\hline Education & 0 & 1 & 3 & 4 & 1 & 0 & 4 & 0 \\
\hline Shelter & 0 & 0 & 4 & 2 & 0 & 0 & 0 & 0 \\
\hline Vulnerability & 1 & 1 & 8 & 2 & 3 & 0 & 5 & 0 \\
\hline Culture Enhancement & 0 & 0 & 4 & 5 & 4 & 0 & 5 & 1 \\
\hline Employment & 0 & 1 & 12 & 9 & 9 & 0 & 12 & 0 \\
\hline Energy security & 0 & 0 & 1 & 1 & 0 & 0 & 0 & 0 \\
\hline Other & 0 & 0 & 1 & 0 & 0 & 0 & 0 & 0 \\
\hline
\end{tabular}

Over half $(n=157,63 \%)$ of the studies that did measure the effect of biodiversity on poverty included some indication of the number of beneficiaries reached and the scale of benefits. However this was hugely variable (from less than ten to several thousand dollars per person per year) and generally not projected beyond the immediate sample size of the study. Less than one-third $(n=78$, $31 \%)$ of studies included any indication of the likely duration of the effect. Of these, the majority $(n=60,77 \%)$ considered it to be long term, 14\% considered it to be short term and 9\% seasonal. Just over one-third $(n=85,34 \%)$ considered the outcomes to be achievable elsewhere beyond the study context.

\section{Outcomes for biodiversity - sustainability of use}

Amongst the studies that employed a measure of contribution of biodiversity to poverty alleviation, only just over half $(n=142,57 \%)$ included any consideration of whether the use of biodiversity was sustainable. Of these use was considered sustainable in $65 \%$ of cases. Most doubts about the sustainability of use were associated with direct (consumptive) use mechanisms. Biodiversity use was considered to be unsustainable in $21 \%$ of direct use studies compared to $13 \%$ for indirect use studies.

\section{Mapping the quality of papers relevant to the question}

Without making any judgements as to the superiority of one research design or method over another we categorized our subset of studies with a poverty measure according to whether they were based on primary or secondary data, and whether they had adopted an experimental, quasi-experimental or non-experimental research design. By experimental design we refer to studies that have a randomised, controlled research design whereas quasi-experimental designs have a control but are not randomised. Non-experimental research designs have no control and encompass a huge range of research methods. It was not possible to determine the research design in all the studies - some reported data without providing any details on how they were obtained. However, the majority of studies ( $n=162,65 \%)$ were based on primary data. Amongst these, the most common research design was non-experimental $(\mathrm{n}=$ $151,93 \%)$. We only identified $11(<5 \%)$ studies that were based on experimental or quasi-experimental research.

We also looked at the extent to which studies had addressed issues which we expected would moderate the biodiversity-poverty relationship. These included the governance regime, resource rights regime, land tenure, power relations, distribution of costs and benefits, and trade-offs. We found that each issue was addressed by roughly half of the studies in each case with the exception of trade-offs which was discussed by just over onethird (36\%) of studies and power relations which was addressed by less than one-quarter (21\%), (Table 4).

\section{Discussion}

\section{Components of biodiversity and dimensions of poverty studied}

It has been noted that studies relevant to links between poverty and biodiversity tend to treat poverty as a unidimensional issue related to income [12]. Our analysis certainly confirmed the dominance of income as a measure of poverty. However, over half the sources of evidence did measure more than one dimension of poverty, challenging the earlier characterization of the literature. 


\begin{tabular}{|c|c|c|c|}
\hline Does the paper consider & Yes & No & $\begin{array}{l}\text { Not applicable/not } \\
\text { mentioned }\end{array}$ \\
\hline Distributional impacts & 126 & 121 & 1 \\
\hline The governance regime & 115 & 107 & 26 \\
\hline The resource rights regime & 128 & 92 & 28 \\
\hline The land tenure regime & 116 & 105 & 27 \\
\hline Power relations & 53 & 188 & 7 \\
\hline $\begin{array}{l}\text { Possible trade-offs/costs as } \\
\text { well as benefits }\end{array}$ & 90 & 157 & 1 \\
\hline
\end{tabular}

A large proportion of all studies either did not mention or did not specify the aspect or dynamic of poverty they were measuring, suggesting that these issues may not have been considered important by researchers. Given the well-established importance of relative versus absolute and temporal versus chronic poverty $[25,27]$ this is an area requiring more research, or at the very least more clarity in future publications.

The dominance of studies in forest systems is interesting, given that poor people make use of biodiversity in a wide range of different ecosystems. It seems unlikely that studies based in forests would be disproportionately likely to be identified by our search, so we suggest that the relationship between poverty and biodiversity in non-forest habitats is an area requiring further study. Drylands, for example are home to a disproportionate proportion of the world's poor whose livelihoods depend on land and livestock [28]. The importance of biodiversity - for fodder, fibre and medicines - seems obvious but is poorly studied and documented [29].

Evidence was found on a wide range of components of biodiversity, with only guilds and genes/germplasm mentioned rarely. The former may be due to 'guild' being a rather specialist term, but the latter indicates a promising avenue for further research on links to poverty. It is interesting, however, to note the lack of studies that consider the importance of diversity per se. Given that by some interpretations biodiversity only refers to diversity, and not other attributes of living organisms, this is perhaps a cause for concern. In most cases the evidence is focused on particular species or the extent/abundance of a set of species with a particular link to poverty, and we do not know enough about issues such as whether such species could be replaced by others performing the same role for the poor, or the role of diversity in providing resilience.

It is perhaps not surprising that the most commonly cited component of biodiversity under study was NTFPs given the preponderance of studies based in forest habitats. This does seem to confirm once again that the evidence base is strongest in regard to the use made of forest products by the poor. An alternative interpretation is that the term NTFP is potentially all-encompassing, prompting Belcher to ask 10 years ago, "what isn't an NTFP?" [30]. We encountered a wide range of species that were classified as NTFPs. Further disaggregation and analysis would provide greater understanding of which particular species - or NTFP properties - appear to be particularly valuable for different groups of poor people in different ecological and governance contexts.

\section{The nature of biodiversity-poverty links}

The evidence base on biodiversity - poverty linkages is dominated by studies of the direct, consumptive, use of biodiversity by people. Very few studies reported negative impacts on poverty, which is partly due to our decision to exclude health impacts of pathogens. Nonetheless, it does seem that there is very little research into negative impacts of biodiversity on poverty beyond human-wildlife conflict studies. Our exercise returned remarkably few studies on issues such as live animal trade, aquaculture and agrobiodiversity. More focussed systematic maps would be useful to determine if this lack of studies is a consequence of the limitations of our search string, or indeed whether further research on these issues is needed.

Because the majority of studies that we found were focussed on the consumptive use of biodiversity by people, it is not surprising that the most common relationships between biodiversity and poverty reported were related to meeting subsistence needs and generating a source of income. Again, more focussed systematic maps would be useful to determine if the limited number of studies we found documenting the effect that biodiversity's role in contributing to long term resilience or acting as a safety net has on poverty reflects a lack of evidence or a limitation in our search.

We were surprised by the number of studies that included no information about the sustainability of biodiversity use given that this is of critical importance to any discussion of the relationship between biodiversity and poverty. Measuring sustainability is clearly challenging, in that it requires long term studies and a sophisticated understanding of ecological processes that produce biodiversity of value to the poor. This is an area clearly in need of further research.

\section{Quality of evidence}

The limited number of studies we found that had adopted experimental or quasi-experimental research designs is consistent with the findings of other researchers who have called for more controlled studies and counterfactual analysis [31]. The majority of our studies, however, describe people's everyday use of and interaction with biodiversity. They are not experiments but real world situations where ideal controls in which 
all variables other than the biodiversity or poverty 'treatment' are the same do not exist. Thus we did not find research design to be a good indicator of quality - although it was equally frustrating to identify case studies - particularly in the grey literature - that presented data without providing any insights into how those data were collected or validated.

We attempted to balance a focus on research design with an assessment of the extent to which key issues that have an impact of the relationship between biodiversity and poverty had been addressed in studies but again the degree to which different issues are relevant in different contexts is highly variable and thus their treatment not a comparable indicator of quality. Further debate is required as to what constitutes high or low quality evidence when attempting to evaluate complex, real-world situations rather than tightly defined interventions with suitable counter-factual sites for analysis [32-34] - particularly if full systematic reviews are conducted in the future to explore more specific questions within the topic of the link between biodiversity and poverty.

\section{Conclusions}

Both "biodiversity" and "poverty" are complex, multidimensional concepts. Searching for relevant literature that addresses the question "Which components of biodiversity affect which dimensions of poverty" meant that we had to cast our net wide in order to capture this complexity - as our search string detailed in Additional file 1 illustrates - but as a result also had to filter out a lot of irrelevant material. While we eliminated the irrelevant material we also recognised that our search has missed areas of relevant literature. This suggests that we may have chosen our initial keywords poorly, and also reinforces the point that no matter how objective and systematic the review, it is only ever as good as the keywords and reviewers.

Shortcomings in our coverage of the specific types of use people make of biodiversity (such as through wildlife trade) could be rectified in subsequent maps by further refinement and testing of our search terms. But in part the limitations of our search are influenced by the complexity of biodiversity and the difficulties in constructing a search string that accounts for that complexity. Thus we have identified no studies, for example, on the role of below-ground biodiversity in maintaining or improving soil productivity which in turn results in improved crop productivity which in turn contributes to increased income and improved food security. While we have sought to map the evidence base it is not clear the extent to which evidence exists and was not captured in our search, or simply does not exist.

Nevertheless, we generated a database of nearly 400 studies that document the influence (positive and negative) of one or more components of biodiversity on one or more dimensions of poverty and within that, a subset of 248 studies that have actually sought to measure that effect in some quantifiable way. While the studies are not directly comparable owing to the wide variety of metrics used as well as the different scale of analysis and study designs, collectively the map can shed light on the validity of claims that conserving biodiversity can reduce poverty. The implications for policy and research are discussed below.

\section{Implications for policy and management}

The map includes evidence on a wide range of different components of biodiversity - but particularly species and ecosystems - affecting different dimensions of poverty particularly income, assets and food security. The overwhelming majority of studies indicates a positive influence of biodiversity on poverty. Caveats aside as to our coverage of biodiversity "dis-services" this implies that development planners should take far more seriously the importance of biodiversity in the lives of poor people. While much lip-service is paid to this relationship, "mainstream" development pathways continue to degrade the natural environment and deplete biodiversity as has been highlighted in numerous analyses - most recently the Millennium Ecosystem Assessment (MA) [35] and the study on The Economics of Ecosystems and Biodiversity [36].

\section{Implications for research}

The systematic map highlighted the difficulties in comprehensively reviewing the evidence on biodiversitypoverty in one study. We have identified a number of apparent gaps in the evidence base but given the difficulties we encountered in ensuring a comprehensive search we would recommend, in the first instance, further analysis to determine which of these are real knowledge gaps that require primary research (as opposed to gaps resulting from limitations of our search strategy). It was noticeable from our map that in the majority of the literature biodiversity is framed in terms of its value as a resource - in the form of specific goods that can be used to generate tangible benefits such as cash, food, fuel. Very few studies explored the underpinning role of biodiversity in ecosystem service delivery - as it is framed in the MA - and fewer really investigated the benefits of genetic diversity in terms of increasing resilience and adaptive capacity. Key areas that we identified for follow-up research are:

- Investigation into the value role of diversity over abundance of resources. The majority of the studies we identified implied that the abundance or availability of particular species or resources was 
more critical than their diversity. Quantifying the value of diversity and where it is particularly important in delivering ecosystem services would make a significant contribution to the biodiversitypoverty debate.

- More research on less tangible components of biodiversity. We found few studies that dealt with genetic diversity, microbes or even invertebrates. The studies that have been undertaken to date barely scratch the surface in terms of the full complement of biodiversity.

- Biodiversity-poverty trade-offs: We were surprised that more studies did not consider the sustainability of biodiversity use. More research into key factors underlying sustainability in different contexts and for different types of use, as well as consideration of thresholds and tipping points would help decisionmakers balance the drive for poverty reduction with the need for biodiversity conservation.

- Long vs short term biodiversity-poverty links: The majority of the evidence we found documented the contribution of biodiversity to short term needs. More analysis is required to uncover the evidence/ generate new evidence on the role of biodiversity in poverty prevention and enhancing longer term resilience.

- Investigation into "policies and institutions that work" in enabling an effective contribution of biodiversity to poverty reduction.

- More detailed, sector-by-sector reviews on key mechanisms for generating value from biodiversity including wildlife trade, crop improvements, fishing etc. - together with an analysis of underlying conditions influencing success or failure.

- Analyses of biodiversity-poverty interactions in non-forest ecosystems particularly those that are home to significant numbers of poor people such as drylands.

One overarching issue, however, that links the policy and research implications is that we currently have no way of knowing how much of "what works" (and is therefore considered of policy relevance) is documented and therefore available for inclusion in systematic maps such as this and able to influence policy. Attention is needed to how better to integrate the documented and undocumented, the "scientific" and traditional in order to generate a much richer evidence base. This is an issue to which the newly established Intergovernmental Panel on Biodiversity and Ecosystem Services (IPBES) is expecting to pay close attention. Its draft work programme for 2014-2018 [37] includes guidance on how to address and include indigenous and local knowledge within its scientific assessments as a key early deliverable.

\section{Additional files}

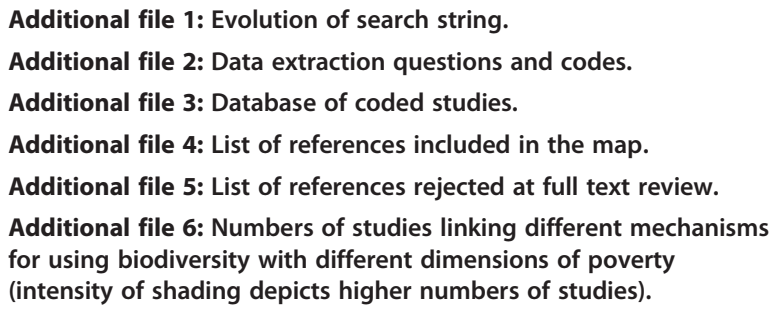

Competing interests

The authors declare that they have no competing interests.

\section{Authors' contibutions}

DR and CS jointly designed the research. DR and MF screened titles and abstracts. DR, MF, MS, AG and AGM screened full text articles. MF and CS conducted the statistical analysis of results. DR and CS drafted the article narrative and MF generated all the figures and tables. All authors read and approved the final manuscript.

\section{Acknowledgments}

The authors would like to thank the Directorate of the ESPA programme for providing the initial funding for this study from its Evidence and Impact Research Grants scheme. Additional funding for products produced under this study has been provided by UKaid from the UK Government however the views expressed do not necessarily reflect the views of the UK Government. Thanks are also due to the three anonymous reviewers of the first draft of this paper who raised a number of very important issues. We hope we have done justice to the comments provided - we feel the paper has benefitted significantly.

\section{Author details}

${ }^{1}$ International Institute for Environment and Development (IIED), 80-86 Grays Inn Road, London WC1X 8NH, UK. ${ }^{2}$ United Nations Environment Programme World Conservation Monitoring Centre (UNEP-WCMC), 219 Huntingdon Road, Cambridge CB3 ODL, UK.

Received: 27 September 2013 Accepted: 2 February 2014 Published: 19 February 2014

\section{References}

1. SCBD: Decision VI/26: Strategic Plan for the Convention on Biological Diversity. Montreal: Secretariat of the Convention on Biological Diversity; 2002.

2. United Nations: Official List of MDG Indicators. 2008. http://mdgs.un.org/ unsd/mdg/Host.aspx?Content=Indicators/OfficialList.htm.

3. Butchart SH, Walpole M, Collen B, van Strien A, Scharlemann JP, Almond RE, Baillie JE, Bomhard B, Brown C, Bruno J, Carpenter KE, Carr GM, Chanson J, Chenery AM, Csirke J, Davidson NC, Dentener F, Foster M, Galli A, Galloway JN, Genovesi P, Gregory RD, Hockings M, Kapos V, Lamarque JF, Leverington F, Loh J, McGeoch MA, McRae L, Minasyan A, et al: Global biodiversity: indicators of recent declines. Science 2010, 328(5982):1164-8.

4. Mace GM, Cramer W, Diaz S, Faith DP, Larigauderie A, Le Prestre P, Palmer M, Perrings C, Scholes RJ, Walpole M, Walther BA, Watson JEM, Mooney HA: Biodiversity targets after 2010. Current Opinion in Environmental Sustainability (COSUST) 2010, 2(1):3-8.

5. United Nations: The Millennium Development Goals Report. New York: United Nations; 2010.

6. United Nations: Secretary-General, at High-Level Meeting, Stresses Urgent Need to Reverse Alarming Rate of Biodiversity Loss, Rescue Natural Economy. 2010. Press Release 22 Sept 2010, http://www.un.org/News/Press/docs/2010/ ga10992.doc.htm.

7. SCBD: Decision X/2: Strategic Plan for Biodiversity 2011-2020. Montreal: Secretariat of the Convention on Biological Diversity; 2010.

8. Millennium Ecosystem Assessment: Ecosystems and Human Wellbeing Biodiversity Synthesis. Washington DC: World Resources Institute; 2005.

9. Kepe T, Saruchera M, Webster WJ: Poverty Alleviation and Biodiversity Conservation: A South African Perspective. Oryx 2004, 38(2):143-145. 
10. Tekelenburg A, ten Brink BJE, Witmer MCH: How do Biodiversity and Poverty Relate? An Explorative Study. Bilthoven: Netherlands Environmental Assessment Agency; 2009.

11. Leisher C, Sanjayan M, Blockhus J, Larsen SN, Kontoleon A: Does conserving biodiversity work to reduce poverty? A state of knowledge review. In Biodiversity Conservation and Poverty Alleviation: Exploring the Evidence for a Link. Edited by Roe D, et al. Oxford: Wiley-Blackwell; 2013.

12. Vira B, Kontoleon A: Dependence of the poor on biodiversity: which poor, what biodiversity? A State of Knowledge Review. In Biodiversity Conservation and Poverty Alleviation: Exploring the Evidence for a Link. Edited by Roe D, et al. Oxford: Wiley-Blackwell; 2013.

13. World Bank: World Development Report 2000/2001: Attacking Poverty. Washington DC: World Bank; 2001.

14. Sen A: Development as Freedom. London: Zed Books; 1999.

15. Clapton J, Rutter D, Sharif N: SCIE Systematic mapping guidance. UK: Social Care Institute for Excellence; 2009.

16. Randall NP, James K: The effectiveness of integrated farm management, organic farming and agri-environment schemes for conserving biodiversity in temperate Europe - A systematic map. J Env Evid 2012, 1:4. doi:10.1186/2047-2382-1-4.

17. Balmford A, Bruner $A$, Cooper $P$, Costanza R, Farber $S$, Green RE, Jenkins $M$, Jefferiss P, Jessamy V, Madden J, Munro K, Myers N, Naeem S, Paavola J, Rayment M, Trumper S, Turner RK: Economic reasons for conserving wild nature. Science 2002, 297:950-953.

18. Mace GM, Norris K, Fitter AH: Biodiversity and ecosystem services: a multi-layered relationship. TREE 2012, 27:19-26.

19. Roe R, Sandbrook C, Fancourt M, Schulte B, Munroe R, Sibanda M: A systematic map protocol: which components or attributes of biodiversity affect which dimensions of poverty. Env Evid, 2(1).

20. Sciverse Scopus. http://www.scopus.com/.

21. Web of knowledge. http://wok.mimas.ac.uk/.

22. Poverty and Conservation Learning Group. www.povertyandconservation.info.

23. IUCN Habitats Classification Scheme (Version 3.1). http://www.iucnredlist.org/ technical-documents/classification-schemes/habitats-classification-schemever3.

24. Lincoln Fishpool: Pers Comm. 2011.

25. Suich H: Conceptual Framework: Poverty. 2012. http://www.espa.ac.uk/files/ espa/Povertyframework.pdf.

26. OECD: "Total Economic Value", in OECD, Cost-Benefit Analysis and the Environment: Recent Developments. Paris: OECD Publishing; 2006. doi:10.1787/9789264010055-7-en.

27. Hulme D, Moore K, Shepherd A: Chronic poverty: meanings and analytical frameworks. Chronic Poverty Research Centre Working Paper no 2. Manchester: University of Manchester; 2001.

28. Millennium Ecosystem Assessment: Ecosystems and Human Well-being: Desertification Synthesis. Washington DC: World Resources Institute; 2005

29. Davies J, Poulsen L, Schulte-Herbrüggen B, Mackinnon K, Crawhall N, Henwood WD, Dudley N, Smith J, Gudka M: Conserving Dryland Biodiversity. Nairobi, Cambridge and Bonn: International Union for Conservation of Nature and Natural Resources, United Nations Environment Programme- World Conservation Monitoring Programme (UNEP-WCMC), and United Nations Convention to Combat Desertification (UNCCD); 2012.

30. Belcher B: What Isn't an NTFP? Int For Rev 2003, 5(2):161-168.

31. Barrett CB, Travis AJ, Dasgupta P: On biodiversity conservation and poverty traps. PNAS 2011, 108(34):13907-13912.

32. Sandbrook C: What Constitutes Good Evidence in the Context of Biodiversity and Ecosystem Services? Poverty and Conservation Learning Group Discussion Paper no 10; 2012. http://pubs.iied.org/G03715.html.

33. Adams WM, Sandbrook C: Conservation, evidence and policy. Oryx 2013, 47(3):329-335
34. Haddaway N, Pullin A: Evidence-based conservation and evidence-informed policy: a response to Adams and Sandbrook. Oryx 2013, 47(3):336-338.

35. Millennium Ecosystem Assessment. www.maweb.org.

36. The Economics of Ecosystems and Biodiversity. www.teebweb.org.

37. Intergovernmental Panel on Biodiversity and Ecosystem Services (IPBES) Draft Work Programme 2014-2018. http://www.ipbes.net/images/IPBES\%20Work\% 20Programme\%20Review\%20Draft\%20-\%20for\%20online\%20review.pdf.

doi:10.1186/2047-2382-3-3

Cite this article as: Roe et al:: Which components or attributes of biodiversity influence which dimensions of poverty? Environmental Evidence 2014 3:3.

\section{Submit your next manuscript to BioMed Central and take full advantage of:}

- Convenient online submission

- Thorough peer review

- No space constraints or color figure charges

- Immediate publication on acceptance

- Inclusion in PubMed, CAS, Scopus and Google Scholar

- Research which is freely available for redistribution

Submit your manuscript at www.biomedcentral.com/submit
C Biomed Central 